\title{
Collections at Risk: Revisiting Serial Cancellations in Academic Libraries
}

\section{Tina E. Chrzastowski and Karen A. Schmidt}

In 1993, Tina E. Chrzastowski and Karen A. Schmidt published a longitudinal study of serial cancellations from five midwestern academic research libraries. ${ }^{1}$ The study found that actual title cancellation overlap was small (4.3\%), meaning that many unique titles were being cancelled. A profile for an "at-risk" serial title, one most likely to be cancelled, was also determined. The titles most often cancelled were English-language titles in the sciences having a higher-than-average subscription price. The present study builds on the original research, adding two more years of cancellation data as well as serial order data. Results show that the rate of cancellations accelerated and that cancellation overlap increased by 55 percent in the two years following the original study. Science titles are still most likely to be cancelled, and less likely to be ordered. Also, the cost of serial cancellations in the sciences is not balanced by orders in the sciences, which are for fewer, lower-priced journals, in contrast with serials in the social sciences and humanities. Overlap in serial orders was less than expected.

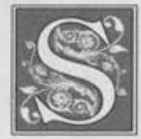

erial cancellations continue to plague our collections and remove unique titles from library shelves. This study documents a dramatic increase in the number of titles cancelled and the number of overlapped serial cancellations between FY91-92 when compared to the previous three years (FY88-90). The new research builds on a previous study conducted in 1992 and published in 1993.2 This study serves to continue to sound the alarm about diminishing serial collections held in academic research libraries.

Intuitively, it seems that little has changed in the way in which libraries have handled serial cancellations in recent years. The effects of the marketplace continue to play havoc with materials budgets; libraries know too little, too late in their budget years to manage many cooperative efforts to protect vulnerable serial titles; and the overall perception is that serial collections are getting leaner, monograph collections are suffering in relative silence, and the depth and richness of library collections are disappearing. The original research that provides the background for this study addressed the issue of diminishing serial collections and described the at-risk serial. It also discussed the need to analyze serial or-

Tina E. Chrzastowski is Chemistry Librarian and Associate Professor of Library Administration, University of Illinois at Urbana-Champaign; e-mail: chrz@ux1.cso.uiuc.edu. Karen A. Schmidt is Acquisitions Librarian and Professor of Library Administration, University of Illinois at Urbana-Champaign; e-mail: karens@ux1.cso.uiuc.edu. 
ders that, regardless of cancellation projects, continue to be placed in research libraries and the desirability of, and problems associated with, conducting a serial overlap study.

The original research posed a number of questions that required further data collection and analysis. This study seeks to answer these questions: Did the low serial cancellation overlap and the overall profile of serial cancellations found in the original research continue? Are highpriced science titles still the most vulnerable in our collections? Through the additional collection of data on serial orders, this study also attempts to answer questions about what is being added to research collections that were also experiencing cancellations. Which collection development trade-offs are being made? Do these trade-offs represent a discernable profile of collection subject trends? How is the overall complexion of serials collections changing?

\section{Hypotheses}

Based on the results of the first study and general perceptions about serial cancellations and orders, several predictions were made. These predictions relate to the different data sets collected from the five libraries. Those data sets included information on both cancellations and orders. The hypotheses for the serial cancellation and order databases are:

- Cancellations will continue to reflect results from the original FY88-90 study, but will accelerate.

- The cancellation overlap (the same titles being cancelled by two or more libraries) will increase.

- There will be fewer serial orders than serial cancellations in both dollar amount and number of orders.

- Orders by subject will not parallel cancella- tions by subject, with a bias against the sciences.

- Order overlap will be greater than cancellation overlap, meaning that libraries will tend to order the same titles and continue to cancel different titles.

\section{Population}

To compare recent data with data from the 1993 study, the same five ARL libraries were selected as the sample group for the follow-up study. These libraries are Michigan State University, Ohio State University, the University of Illinois at Urbana-Champaign, the University of Iowa, and the University of Wisconsin at Madison. Each of these libraries is a member of the Committee on Institutional Cooperation (CIC), a consortium of midwestern academic institutions. The libraries of the CIC have a history of shared cooperative ventures, as well as the common characteristic of owning and maintaining large, research-oriented collections in virtually every discipline.

Table 1 shows FY91-92 serial expenditures for the five libraries taken from ARL statistics. ${ }^{3}$ Only two of the five libraries experienced increased serial budgets (averaging only two percent), and three libraries' serial budgets decreased from FY91 to FY92 (an average of three percent). Among the five libraries, FY91-92 serial expenditures decreased an

\begin{tabular}{|c|c|c|c|}
\hline \multicolumn{4}{|c|}{$\begin{array}{c}\text { TABLE 1 } \\
\text { Total Expenditures for Serials, FY91-92, and } \\
\text { Percent Change for the Five Libraries in the Study }\end{array}$} \\
\hline & FY91 & FY92 & $\%$ Change \\
\hline Illinois & $\$ 3,707,269$ & $\$ 3,807,387$ & $+3 \%$ \\
\hline Iowa & $2,670,813$ & $2,548,192$ & -5 \\
\hline Michigan State & $2,607,306$ & $2,520,018$ & -3 \\
\hline Ohio State & $4,113,097$ & $4,163,453$ & +1 \\
\hline Wisconsin & $4,084,110$ & $4,035,678$ & -1 \\
\hline \multicolumn{2}{|c|}{ (From ARL Statistics) } & Average & -1 \\
\hline
\end{tabular}




\begin{tabular}{|llll|}
\hline \multicolumn{4}{c|}{ TABLE 2 } \\
Percent of Total Budget Spent on Serials, FY91-92, and \\
Percent Change for the Five Libraries in the Study
\end{tabular}

for the original 1992 study. Serial cancellation data for FY91-92 were requested from each of the five libraries in the original study. The lists of serial titles were input into a database with nine fields for each title: title, price of title in the year cancelled, place of publication, language (English or

average of one percent. This compares to a nine percent increase in serial expenditures for FY88-90.4 Also, despite some overall materials budget increases, each library also reported serial cancellations for these years. In fact, serial cancellations accelerated during the two years following the original study, with slightly more cancellations during the two-year period of FY91-92 (6,518 cancellations) than had occurred during the three years covered by FY88-90 (6,503 cancellations).

Table 2 shows the percent of these libraries' total FY91-92 budgets devoted to serial purchases taken from ARL statistics. Each library decreased the percentage of its total materials budget allocated to purchase serials between FY91 and FY92. These reductions could be a result of efforts to balance the percentage of total budgets spent on serials and monographs. They also could represent attempts to gain control over constantly rising serial prices. For FY88-90, a threeyear period, serial expenditures by the five libraries accounted for an average of 57.4 percent of these libraries' materials budgets. ${ }^{5}$ By FY91-92, however, the five libraries were spending an average of 58.8 percent of their total materials budgets on serials, despite an acceleration in serial cancellations.

\section{Methodology}

The follow-up study used a research methodology identical to that employed
non-English), year of cancellation, $\mathrm{Li}$ brary of Congress (LC) call number, an indication of whether the journal was received as a gift (if reported), an indication of whether the journal was a duplicate at that location (if reported), and which library cancelled the title. Each field was made searchable and sortable so that the data could be examined in any combination and also could be compared to the original research database (containing cancellation data for fiscal years 1988 , 1989, and 1990).

Data on serial orders for FY88-92 were also requested from the five libraries in order to begin comparing the balance between serial titles lost and gained. Order data were more difficult to provide for many of the libraries; the result was a limited database of serial orders from four schools, covering fiscal years 1990, 1991, and 1992. (Wisconsin was unable to provide serial order information at the time of the study.) For comparison purposes, a working portion of the cancellation database was created to match the order database. It too covers four libraries (without Wisconsin cancellation data), FY90-92.

The authors received incomplete data from each library. In order to complete all or most of the nine fields for each title, a number of other resource tools were used. These included the OCLC database, Ulrich's International Periodical Directory, Faxon's Librarian's Guide to Serials, the 
University of Illinois' online catalog, Illinet Online, and MELVYL, the online catalog of the University of California libraries. Even with this careful checking, some fields remained unfilled. When reporting the results, the percentage of complete information for that field is included in the analysis.

Data analyses were conducted using SPSS-PC, a software analysis program

Total cancellations for the fiveyear period numbered 13,021.

These total serial cancellations represent a 5.7 percent decrease in serial titles owned over five years based on total holdings reported by the five libraries in FY88.

that is compatible with PC-File, the software used to create the different databases. Different analyses were possible using the searchable indexing assigned to each field. Reports were created based on questions posed by the hypotheses.

\section{Results: FY91-92 Cancellation Data \\ Total Cancellations}

Total cancellations for the five schools rose during the two years following the initial study. Cancellations FY88-90 (three years) totalled 6,503; for FY91-92 (two years), cancellations totalled 6,518. Table 3 provides a comparison overview of data collection for the two data sets. Total cancellations for the five-year period numbered 13,021 . These total serial cancellations represent a 5.7 percent decrease in serial titles owned over five years based on total holdings reported by the five libraries in FY88. However, these libraries paid 30.5 percent more in serial expenditures for 5.7 percent fewer titles during FY88-92.

The number of overlapping (same) titles that were cancelled between libraries during FY91-92 totalled $474(7.2 \%)$, an increase of 55 percent over FY88-90. Ex-

\section{TABLE 3}

\section{Overview of Data Collection Results from the Five Schools} for FY88-90, FY91-92, and Combined F88-92

\begin{tabular}{|c|c|c|c|}
\hline & $\begin{array}{c}\text { FY88-FY90 } \\
\text { (3 years) }\end{array}$ & $\begin{array}{c}\text { FY } 91-\mathrm{FY} 92 \\
\text { (2 years) }\end{array}$ & $\begin{array}{l}\text { FY88-FY92 } \\
\text { (5 years) }\end{array}$ \\
\hline $\begin{array}{l}\text { Number of titles } \\
\text { cancelled }\end{array}$ & 6,503 & 6,518 & 13,021 \\
\hline $\begin{array}{l}\text { Number of same-title } \\
\text { cancellations (duplicat } \\
\text { overlap) }\end{array}$ & ate & 474 & 1,084 \\
\hline $\begin{array}{l}\text { Percent of cancellations } \\
\text { representing unique } \\
\text { titles cancelled }\end{array}$ & s $95.7 \%$ & $92.8 \%$ & $91.7 \%$ \\
\hline $\begin{array}{l}\text { Total dollar value of } \\
\text { cancellations }^{1}\end{array}$ & $\$ 690,225.64$ & $\$ 1,031,584.50$ & $\$ 1,721,810.14$ \\
\hline $\begin{array}{l}\text { Average cost of a } \\
\text { cancelled title }{ }^{2}\end{array}$ & $\$ 121.71$ & $\$ 193.43$ & $\$ 151.31$ \\
\hline \multicolumn{4}{|c|}{$\begin{array}{l}{ }^{1} \text { For FY88-90, approximately } 7 \% \text { of titles could not be assigned prices; for FY91-92, } \\
\text { approximately } 18 \% \text { of titles could not be assigned prices. Therefore prices are conserva- } \\
\text { tive estimates. }\end{array}$} \\
\hline \multicolumn{4}{|c|}{$\begin{array}{l}{ }^{2} \text { Average is based on the number of titles with prices: } 93 \% \text { of FY88-90 titles have prices } \\
\text { and } 82 \% \text { of FY91-92 titles have prices. }\end{array}$} \\
\hline
\end{tabular}


amination of the overlap for the total five years of cancellation data shows an overlap rate of 8.3 percent. Duplicate titles that were cancelled by four or five schools include Chemical Abstracts, Books in Print, Methods of Biochemical Analysis, Public Administration Review, Progress in Oceanography, Soviet Electrochemistry, and Who's Who in America. Although duplicate titles still represent a small fraction of cancellations, this increase in overlap suggests the continuation of a trend for libraries to cut more heavily into their core collection.

\section{Serial Cancellation Prices}

The total price of serial cancellations for the five schools also continued to rise: cancellations totalled $\$ 690,225.64$ for FY88-90, and \$1,031,584.50 for FY91-92. The dollar value of cancellations increased 49 percent in a one-third shorter time period. Price information for FY9192 was available for only 82 percent of the titles, so these totals are conservative estimates.

The average cost of a cancelled serial found in the FY88-90 study was \$121.71. According to annual serial surveys for 1991 and 1992, serial price increases raised the average price of a serial to $\$ 158.53$ for 1991 and to $\$ 170.93$ for $1992 .^{6}$ The study also found an average serial price (FY91-92) of $\$ 193.43,13$ percent higher than the average reported by the annual serial surveys. These findings continue the trend in these five libraries of cancelling higher-than-average-priced journals.

\section{Language and Place of Publication}

To simplify data collection, there were only two language categories assigned: English and non-English. More than 99 percent of the titles had language data assigned. Results indicate that 80.5 percent of the titles cancelled were English language and 19.5 percent were non-English language. Data for FY88-90 also showed a predominance of English-language cancellations, with the ratio being
74 percent English and 26 percent nonEnglish.

The authors collected data on place of publication and divided the information into two categories: U.S.-published and non-U.S.-published titles. Information on place of publication was assigned to more than 98 percent of the titles. For FY91-92, non-U.S.-published titles represented 55.4 percent of all cancellations, and U.S.-published titles represented 44.6 percent. Data from the earlier study showed similar findings, with non-U.S.-published titles at 53 percent of cancellations and U.S.published titles at 47 percent. Thus, there is a clear continuing trend of cancellation of nondomestic titles.

\section{Library of Congress Subject Classification}

More than 97 percent of the titles in the FY91-92 cancellation database were assigned an LC subject classification. Figure 1 shows LC classification distribution for the entire FY91-92 database. As was the case in the first study, the largest subject group of cancelled titles was Q-class (science) serials, accounting for 21 percent of the total database. In FY88-90, Q-class accounted for 19 percent of all cancellations; therefore, Q cancellations increased 10 percent between FY88-90 and FY91-92. Cancellations in the science-technologymedicine call number ranges-Q (science), $\mathrm{R}$ (medicine), $\mathrm{S}$ (agriculture), and $\mathrm{T}$ (technology) - rose from 40 percent of total cancellations in FY88-90 to 45.6 percent in FY91-92. Again, FY91-92 represents a one-third shorter time span than the original database. These data make clear the acceleration in the cancellation of science serials.

\section{Results: FY90-92 Order Data Total Orders}

As noted earlier, librarians continue to place orders for serials in research libraries even during years of serious budget cuts. A look at serial orders helps to clarify the emerging patterns of serial collections and describes the overall collecting 
FIGURE 1

LC classification distribution for 6,518 serial cancellations for five libraries in study, FY91-92

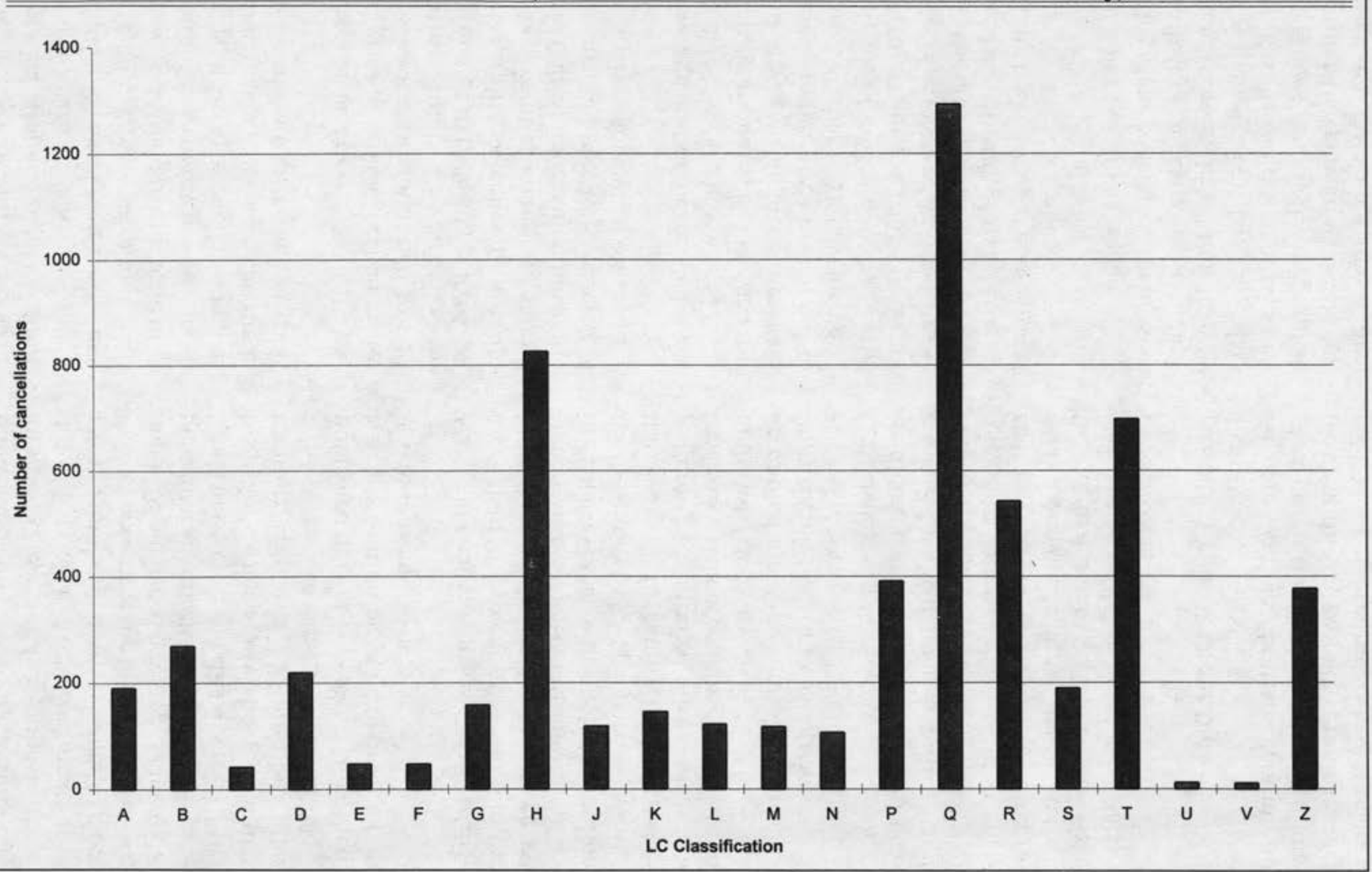


trends. Also, it not only helps to describe the type of serial that is most likely to be purchased but also, by default, reinforces the portrait of the at-risk serial. During FY90-92, four libraries placed 5,643 orders for new serials. (As noted earlier, order data were not available from Wisconsin.) As predicted by budget expenditures in table 1, the library that spent the most on serials, Ohio State University, ordered the highest number of serials. Overlapping orders (i.e., titles ordered by two or more libraries) totalled 383 titles (5.8\% of the total number of titles ordered). Fewer than one percent of the titles were ordered by three or four schools, and only 4.6 percent were ordered by two of the schools. Titles that were ordered by three or more of the libraries were most often CD-ROM products, including Agricola CD-ROM, Medline $C D$-ROM, PsychLit CD-ROM, and Current Contents on Diskette (all titles in the series). In addition, print titles ordered by three or more libraries included Harvard Papers in Botany, Journal of East Asian Linguistics, Southeastern Journal of Music Education, and Foreign Policy Bulletin.

\section{Serial Order Prices}

Whereas the average list price for serials for 1991 and 1992 was approximately $\$ 165$, orders from the four test libraries averaged significantly lower at $\$ 107.73$ (based on $77 \%$ of the orders with an assigned price). As discussed later, this may be a reflection of the subject content of the serials. Only nine percent of the titles ordered cost more than $\$ 200$, with the vast majority (79\%) costing less than $\$ 100$.

\section{Language and Place of Publication}

Place of publication (U.S. or non-U.S.) and language (English or non-English) were assigned to 99 percent of the serials ordered. Serial titles ordered were overwhelmingly English (88.4\%); only 11.6 percent were non-English. Of the titles ordered, 60.2 percent were published in the United States. These results reflect not only a selecting bias toward English-language domestic titles, but also undoubtedly the realities of the marketplace that continue to focus on English-language publications from publishing houses with international offices (i.e., Europe and the United States).

\section{Library of Congress Classification}

LC classification numbers were assigned to 98 percent of the titles in the order database. The greatest activity in serial ordering occurred in the general social science $(\mathrm{H})$ classification, which accounted for 20 percent of all orders placed. Sciences (classes Q, R, S, and T) accounted for only 11.4 percent of new orders. Language and literature titles, in the P classification, totalled 10.9 percent of all orders.

\section{Fewer than one percent of the titles were ordered by three or four schools, and only 4.6 percent were ordered by two of the schools.}

Classification order data by cost are displayed in figure 2, in juxtaposition with the cost of serial cancellations by classification. As indicated earlier, the lower expenditures in serials, and the acquisition of titles costing less than $\$ 100$, probably reflects the generally lower costs of serials in the social sciences and humanities.

\section{FY90-92 Order and Cancellation Data Compared}

The authors conducted a number of analyses comparing the FY90-92 order and cancellation databases. As previously stated, these files were created using order data provided by four of the five schools. The participating schools were the University of Illinois at UrbanaChampaign, the University of Iowa, Michigan State University, and Ohio State University. A file matching the four schools' cancellation data for FY90-92 


\begin{tabular}{|c|c|}
\hline \multicolumn{2}{|c|}{$\begin{array}{c}\text { TABLE 4 } \\
\text { Data Comparing Orders and } \\
\text { Cancellations, FY90-92 }\end{array}$} \\
\hline Number of cancelled titles & $\begin{array}{c}6,025 \\
\text { (92.9\% unique) }\end{array}$ \\
\hline Number of orders placed & $\begin{array}{c}5,643 \\
\text { (93.3\% unique) }\end{array}$ \\
\hline Dollar value of cancellations* & * $\$ 919,422.47$ \\
\hline Dollar value of orders placed* & * $\quad \$ 607,908.18$ \\
\hline \multicolumn{2}{|c|}{$\begin{array}{l}26 \% \text { of cancellation records for this time period } \\
\text { could not be assigned price; } 23 \% \text { of order records } \\
\text { for this time period could not be assigned price. } \\
\text { Therefore, the dollar values are conservative } \\
\text { estimates. }\end{array}$} \\
\hline
\end{tabular}

also was created for comparison purposes.

\section{Total Cancellations/Total Orders \\ Compared}

Cancellations and orders for FY90-92 are shown in table 4 and figure 2 . In terms of numbers, there were approximately six percent fewer orders than cancellations. In terms of dollars, 51 percent fewer dollars were spent on orders than were made through cancellations, indicating either a diversion of money to cover increased costs of serial subscriptions that were maintained or a shift in budgeting to new resources.

Figure 2 shows orders and cancellations compared by subject classification. This figure highlights the subjects in which the greatest amount of activity occurred, both positive and negative. Within this study, a major shift is taking place as dollars are moved from science titles and then are added to social science and literature titles. Table 5 looks specifically at orders and cancellations (both price and number) for call numbers for these disciplines. Call numbers Q (science), $\mathrm{H}$ (social science), K (law), and P (literature) show the greatest percentage changes in figure 2. Table 5 examines these ranges and adds data for QRST (all sciences). The positive increases in the social sciences and literature call number areas are nearly as dramatic as the negative losses in the science call number areas.

Analysis on a title-by-title basis also indicates the first stirrings of a shift from print sources to CD-ROM formats in the sciences. Eighty-one titles $(1.4 \%$ of all orders) were for CD-ROMs, whereas only eight CD-ROM titles were cancelled (13\% of cancelled titles for FY90-92). New serials in these collections also appear to include several indexes and reference sources on the part of the sciences. Serial orders in the humanities and social sciences appear to remain with print-based publications.

\section{Orders and Cancellations by Cost}

Figure 3 shows two pie charts comparing orders and cancellations broken down into three subscription price categories: less than $\$ 100$, between $\$ 100$ and $\$ 200$, and greater than $\$ 200$. An obvious move away from high-priced journals is found. This result could be expected because of

\begin{tabular}{|lrrrrrr|}
\hline \multicolumn{7}{|c|}{ TABLE 5 } \\
& $\begin{array}{l}\text { Order and Cancellation Data Comparisons, } \\
\text { FY90-92 by Subject with Percent Change }\end{array}$ \\
\hline \hline & \# Cancelled & \# Ordered & \$Cancelled & \$ Ordered & \\
\hline H (social science) & 826 & 1,129 & $(+37 \%)$ & $\$ 57,593.29$ & $\$ 105,806.86$ & $(+84 \%)$ \\
K (law) & 145 & 325 & $(+124 \%)$ & $26,726.27$ & $59,867.50$ & $(+124 \%)$ \\
P (literature) & 391 & 613 & $(+57 \%)$ & $17,446.60$ & $37,964.31$ & $(+117 \%)$ \\
Q (science) & 1,293 & 644 & $(-50 \%)$ & $375,544.82$ & $143,435.73$ & $(-61 \%)$ \\
QRST (all sciences) & 2,722 & 1,414 & $(-48 \%)$ & $613,756.77$ & $232,838.61$ & $(-62 \%)$ \\
\hline
\end{tabular}


FIGURE 2

Total cost of serials ordered and cancelled by LC classification for four schools in study, FY90-92

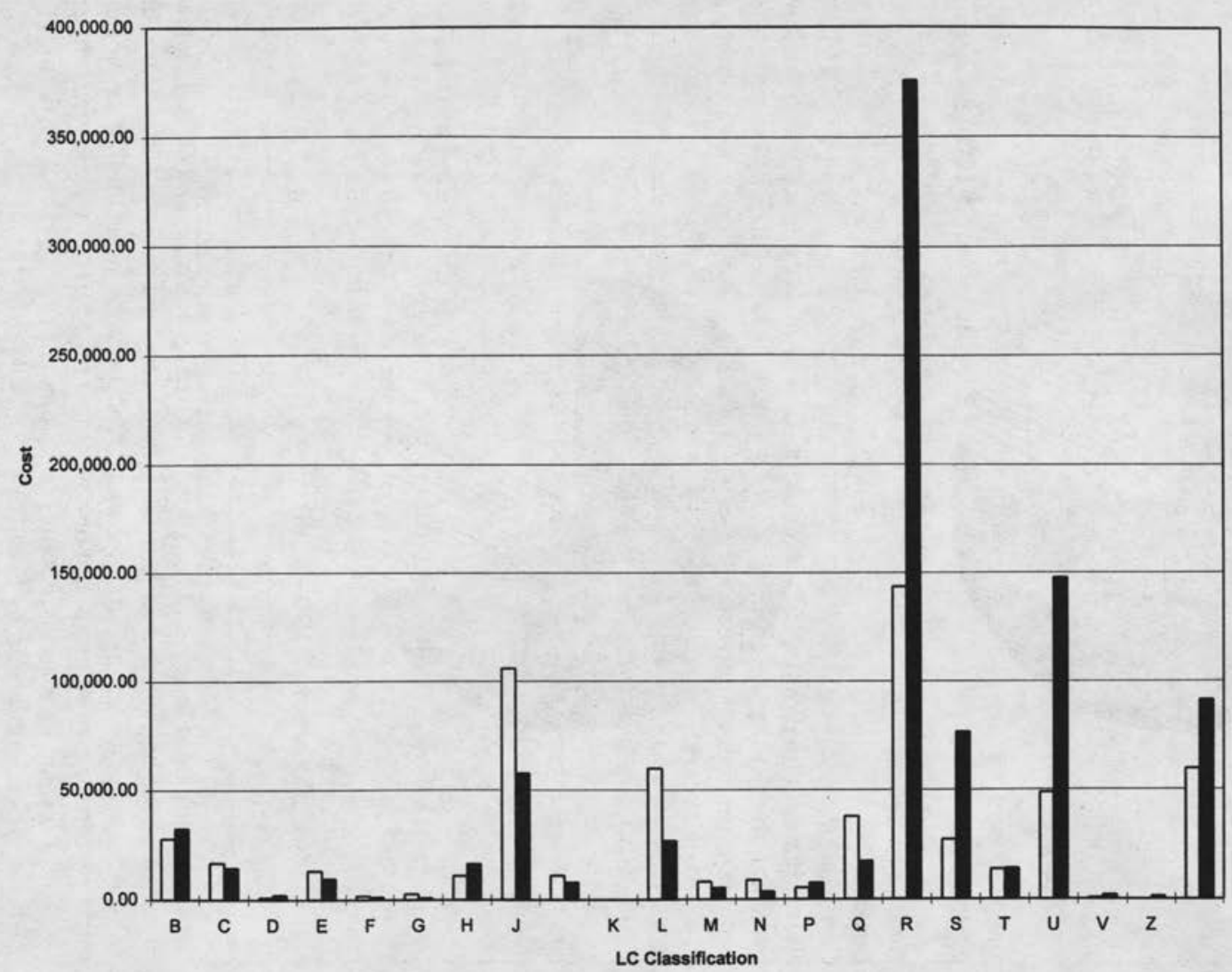




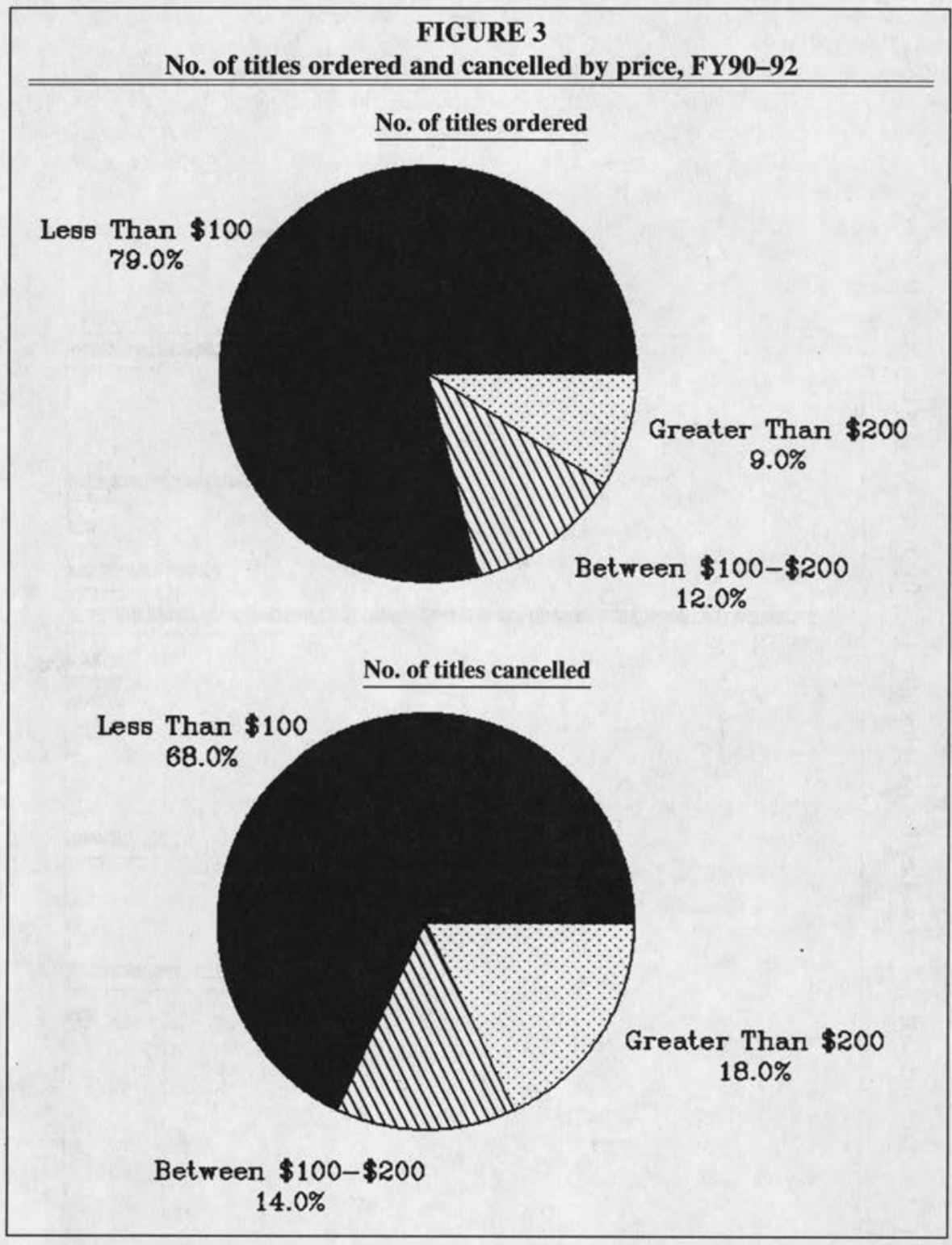

the large number of science cancellations (the area of the highest-priced journals). Subscriptions priced over $\$ 200$ account for 18 percent of cancellations, but only 9 percent of orders. Increases are found in the lower-priced subscriptions. Subscriptions priced under $\$ 100$ account for 68 percent of cancellations and rise to 79 percent of orders.
Overlap in Orders and Cancellations

As reported earlier, overlap (cancellations of the same titles by two or more libraries) for FY91-92 was 7.2 percent and 8.3 percent overall (FY88-92 data). This is a small portion of all cancellations and suggests that research libraries are continuing to chisel away at their unique publications. However, the implication is that 
the cancellation overlap is growing, bringing with it an ever-smaller group of core journals that may be duplicated from library to library and, in the future, may be online, full-text journals that are easily accessible. This movement toward similar collections, in tandem with the electronic initiatives that several of the larger publishing houses are making, indicates a research community far less deep and rich than was previously the case.

The surprise, and perhaps the mitigating factor in this gloomy future, is the lack of overlap in serial orders. It had been expected that orders will be highly duplicative, but only 6.8 percent were ordered by two or more schools. The problem with drawing too strong a conclusion on these data is the shortness of time for the study. Collection development officers of the CIC libraries, when asked about this low overlap figure, suggest that although there is no mechanism in place to check other libraries' holdings before placing an order, there is reliance on CRL holdings to avoid ordering some titles. There also might be in this a suggestion that these institutions, while maintaining very similar research programs in a broad sense, can concentrate on very different aspects of a discipline and that libraries are now buying on a "micro" level as opposed to a "macro" level because of the pressures of the marketplace.

\section{At-risk/Not-at-risk Journal Profiles}

Finally, these data suggest the profile of journals at risk for cancellation and those likely to be ordered. Data from the previous study identified an "at-risk journal" as a higher-than-average-priced, Englishlanguage science title. The results of two more years of data do nothing to dispel this image. On the contrary, it is even more evident that science titles are at risk and that the cost of journals is driving cancellation decisions.

Conversely, "not-at-risk journals" appear to be those in social science fields, again in the English language, with a price tag of under $\$ 100$. Also, although it may appear from the data that social science and humanities serials are surging ahead of the sciences, it is perhaps more likely that journal-buying habits in the social sciences and humanities have not

\section{It had been expected that orders will be highly duplicative, but only 6.8 percent were ordered by two or more schools. The problem with drawing too strong a conclusion on these data is the shortness of time for the study.}

had to change as much as those in the sciences, an area in which rising prices devour huge portions of library materials budgets. One lesson might be that a well-designed, scholarly social science or humanities journal with a reasonable price tag will continue to do well in the library market and with the community of scholars.?

\section{Conclusions}

All but one of the hypotheses were supported. As predicted, the data collected as follow-up to the original 1993 study parallel its results and point to continued serial cancellations at an increased rate. The at-risk serials described in the original study continue to be expensive, English language, foreign-published science titles. They appear to be at risk for cancellation not just today, but also almost certainly in the future. There is no doubt that the sciences, with their high-priced titles and whose funds command a large percentage of not just library serial budgets but the entire library materials budgets, are definite targets for methodical reduction.

Overlap of cancelled titles increased by 55 percent between FY88-90 and FY9192, jumping from 4.3 to 7.2 percent of total cancellations ( $8.3 \%$ overall). This increase can be explained by examining how collections and resulting cancellations are structured. Figure 4 shows a tar- 
get representing academic library serial collections. The center of the target is the core serial collection-those titles with high-impact factors, high use, and which are duplicated in nearly every academic library. ${ }^{8}$ The concentric rings radiating from the core represent steps away from the core-those titles that are incrementally less frequently used and less frequently cited. The outermost ring is where cancellations begin and overlap among libraries of similar size and mission is less likely. The peripheral titles of the outer rings are among the first to be cancelled. Figure 4 shows that cancellation overlap in the original study (FY88-90) measured 4.3 percent. As cancellations continue and move toward the core, overlap among cancelled titles grows. This accounts for the increased overlap of 7.2 percent found in the FY91-92 data. For the five-year period FY88-92, the cancellation overlap is 8.3 percent. The cancellation overlap percentage will probably grow as libraries are forced to cancel and still maintain a core group of serials.

As predicted, there were fewer new serial orders than serial cancellations for the FY90-92 period. This dramatic shift is symptomatic of the inability of libraries to keep pace with the serial publishing market and is strongly indicative of the effect of the marketplace on collection decisions. It also was hypothesized that orders would not parallel cancellations in terms of subject. This hypothesis also was proven true: 2.5 times more science titles were cancelled than were ordered. Conversely, twice as many social science titles were ordered as were cancelled.

Finally, the authors predicted that libraries would tend to cancel different titles and order the same title (i.e., that overlap between orders would be greater than overlap between cancellations). The

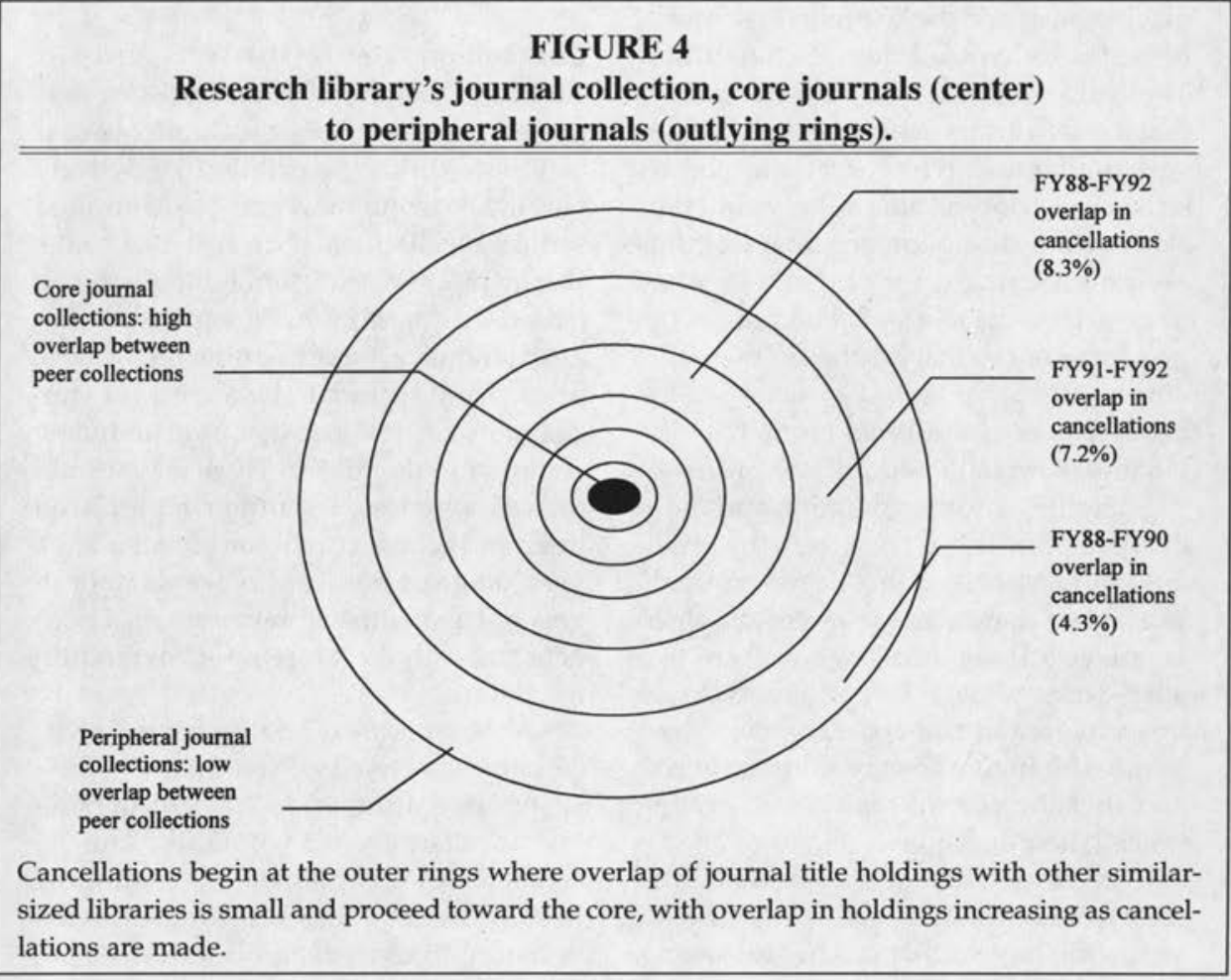


surprise finding of the data collected for FY90-92 shows that serial order overlap was less than serial cancellation overlap and, therefore, the hypothesis predicting the opposite outcome is not supported. The vast majority of cancellations $(92.9 \%)$ were unique to the study group, and 93.3 percent of orders were unique to this group. These nearly identical figures appear to support the continuing existence of diversity in academic library collections. However, because the data cover only a two-year period and have not been verified by a follow-up study, a broader study of a longer period of time would be required to support the notion of retained diversity in academic library orders.

The acceleration toward cancellations of foreign materials and higher Englishlanguage cancellations may be accounted for by examining a similar trend toward science subject-classed cancellations. Many sciences titles, even those originating in foreign countries, are published in English. Tony Stankus et al. studied the trend toward translating foreign-language titles into English and found that science titles published in Germany showed an increase from 1960 to 1978 in the number of articles published in English. ${ }^{9}$ This demonstrates a shift toward English-language publication for foreign-published science journals and could account for the predominance of English-language titles from outside the U.S. being targets for cancellation, particularly given that $\mathbf{4 5 . 6}$ percent of all cancellations in the past two years of the study are science titles.

\section{Future Research}

The need to conduct research on entire serial collections is obvious. The best way to understand the whole picture is to look collectively at serials that are being added and lost. The problems in doing this are technical, not intellectual. When the technical difficulties of sharing complete serial information are solved, so will be many other issues associated with serial collection development. Those issues in- clude broad communication of cancellation decisions, holdings information, and acquisition decisions. There is a continuing need for consistent and timely data from libraries documenting the cuts that are occurring annually. This lack of data hampers efforts to document in an orderly way what is happening, and prevents libraries from making informed decisions about the future.

The most important type of research that needs to be linked with this study are investigations of the effect of these serial cuts on the users of the collections. These effects can be charted by following local journal use, interlibrary use, and the traffic found on online citation/full-text databases such as CARL UnCover. At the end of the day, the most important question is: Are users being given access to the materials they need?

\section{Summary}

The trend that is beginning to take shape after examining these five years of research is for libraries to move slowly toward a core list of serial titles that will satisfy the mainstream and, perhaps, to add serial titles in very discrete portions of disciplines that are unique to each institution. Although the original motivating thought behind this research is that research libraries were cancelling the same titles, it is more likely that these libraries are cancelling the same kind of titles. The same prospect is true for orders. Research libraries belong to the same genus, but not necessarily the same species. It is important for libraries to reflect the persona of the institutions they serve, to have the information necessary to build collectively with other research library partners to support a larger research agenda that is beneficial to many institutions and many researchers, and to avoid the "minimums and ho hums" that reliance on core collections can bring. ${ }^{10}$

In 1994, Anna Perrault reported on research documenting the decline of the monograph in research libraries. ${ }^{11} \mathrm{Her}$ 
conclusions (that monographic collections are becoming more similar and that the core is under attack) unhappily mirror the conclusions of both the present and previous serial study. Perrault's work also urges similar deductions from the results of the study reported here: that the base of information found in traditional serial publications is dwindling; that the marketplace has become the academic library community's collection policy; that communication among collection development librarians will need to be quick and responsive; and that, as Perrault notes, "... resource sharing will need to be a global cooperative effort."12

The conclusions of this study, like Perrault's research, echo in many respects the conclusions of the Mellon Foundation report, University Libraries and Scholarly Communication, wherein the dynamics of serials collections are described in terms of the effects of the marketplace and the problems associated with science-based journals are found to be the most acute. ${ }^{13}$ This report further notes: "In the face of this pricing crisis, libraries have responded by essentially redistributing their resources, a mode of response that cannot go on indefinitely ... there is a growing realization that no research institution can hope to sustain a self-sufficient collection into the indefinite future."14 This fundamental statement of reality is reflected in the specifics of this study of five research libraries over a period of five years. The best hope, when observing the trend of individual collections losing their unique characteristics, is for these institutions to marshal the new tools available to redesign the way libraries interact and manage their collections.

$A u$. note: The authors wish to acknowledge the work of graduate assistant Xiaoyu Zhang and the financial support of the University of Illinois at Urbana-Champaign's Research Board and the University Library Research and Publication Committee.

\section{Notes}

1. Tina E. Chrzastowski and Karen A. Schmidt, "Surveying the Damage: Academic Library Serial Cancellations 1987-88 through 1989-90," College and Research Libraries 54, no. 2 (Mar. 1993): 93-102.

2. Ibid.

3. Association of Research Libraries, ARL Statistics 1990-91 and ARL Statistics 1991-92 (Washington, D.C.: ARL, 1992, 1993).

4. Chrzastowski and Schmidt, "Surveying the Damage," 95 (table 1).

5. Ibid.

6. Kathryn Hammell Carpenter and Adrian W. Alexander, "Periodical Price Index 1992," Library Journal 117 (Apr. 15, 1992): 55-62.

7. This conclusion was also reached by Walt Crawford and Michael Gorman in Future Libraries: Dreams, Madness, \& Reality (Chicago: ALA, 1995), chapter 9, especially pp. 145-47.

8. The term impact factor refers to the ratio between citations and citable items published. For more information, see the introductory material to Journal Citation Reports (ISI publishers) or see Eugene Garfield, "Citation Analysis As a Tool in Journal Evaluation," Science 178 (1972): 471-79.

9. Tony Stankus, Rashelle Schlessinger, and Bernard S. Schlessinger, "English Language Trends in German Basic Science Journals: A Potential Collection Tool," Science and Technology Libraries 1, no. 3 (1981): 55-66.

10. William E. McGrath, "Collection Evaluation-Theory and the Search for Structure," Library Trends 33 (winter 1985): 241-66.

11. Anna H. Perrault, "The Shrinking National Collection: A Study of the Effects of the Diversion of Funds from Monographs to Serials on the Monograph Collections of Research Libraries," Library Acquisitions: Practice and Theory 18, no. 1 (1994): 3-22.

12. Ibid., 16.

13. Anthony M. Cummings, Marcia L. Witte, William G. Bowen, Laura O. Lazarus, and Richard H. Ekman, University Libraries and Scholarly Communication (Washington, D.C.: ARL for the Andrew W. Mellon Foundation, 1992).

14. Ibid., xxii. 